\title{
The Electrochemistry of Iridium Oxide Films in Some Nonaqueous Solvents
}

\author{
Peter G. Pickup ${ }^{* 1}$ and Viola I. Birss* \\ Department of Chemistry, University of Calgary, Calgary, Alberta, Canada T2N 1N4
}

\section{ABSTRACT}

Ir oxide films, grown in aqueous $\mathrm{LiClO}_{4}$ solutions $(p \mathrm{H} \sim 9)$, have been found to exhibit excellent charge capacities, charging and discharging kinetics, and stability in acetonitrile and propylene carbonate with $\mathrm{LiClO}_{4}$ as the supporting electrolyte, while the results in THF also appear to be quite promising. The oxide is electrochromic in all of these media. In order to obtain the optimum response of Ir oxide in nonaqueous solutions, it is important to prevent the drying out of the oxide when transferring it from the aqueous to nonaqueous media. Discharging and charging of the oxide appears to involve $\mathrm{Li}^{+}$insertion and expulsion from the oxide, respectively. Oxides formed in neutral aqueous $\mathrm{LiClO}_{4}$ solutions have been found to be mechanically more stable than those grown in aqueous $0.5 \mathrm{M} \mathrm{H}_{2} \mathrm{SO}_{4}$ or in $50 \%$ aqueous acetonitrile/ $\mathrm{LiClO}_{4}$. This is supported by SEM evidence of a less cracked and more adherent Ir oxide film when grown in neutral aqueous $\mathrm{LiClO}_{4}$ solutions, as compared to the case in the latter solutions.

Hydrous iridium oxide films, grown at Ir electrodes under potential cycling conditions in aqueous media, exhibit a very rapid and reversible Ir(IV)/Ir(III) redox reaction in aqueous solutions (1-5). In aqueous acid solutions, charge neutrality is maintained during reduction (and oxidation) by the injection (and ejection) of protons and anions $\left(\mathrm{X}^{-}\right)$(reaction $\left.[1]\right)(4,6)$

$\left[\mathrm{Ir}(\mathrm{IV}) \mathrm{oxide} \cdot x \mathrm{H}_{2} \mathrm{O}\right]_{5}+5 e^{-}+7 \mathrm{H}^{+}+2 \mathrm{X}^{-}$

$$
=\left[\mathrm{H}_{7}\left(\mathrm{Ir}[\mathrm{III}] \text { oxide } \cdot x \mathrm{H}_{2} \mathrm{O}\right)_{5}\right]^{2+}\left(\mathrm{X}^{-}\right)_{2}
$$

We have shown that in neutral aqueous solutions containing $\mathrm{Li}^{+}$ions, insertion of these metal ions into the oxide can occur rapidly during oxide reduction (reaction [2]) (6), although these ions are replaced by protons with time.

$$
\begin{aligned}
& {\left[\operatorname{Ir}\left(\text { IV)oxide } \cdot x \mathrm{H}_{2} \mathrm{O}\right]_{5}+5 e^{-}+4 \mathrm{H}_{2} \mathrm{O}+\mathrm{M}^{+}\right.} \\
& =\left(\mathrm{M}^{+}\right)\left[\mathrm{H}_{4} \mathrm{Ir} \text { (III)oxide } \cdot x \mathrm{H}_{2} \mathrm{O}\right]^{-}+4 \mathrm{OH}^{-}
\end{aligned}
$$

If this type of ion insertion reaction would occur rapidly in nonaqueous media, then Ir oxide would be potentially useful as a cathode in secondary Li-based batteries.

Several groups have investigated the electrochemistry of hydrous Ir oxide films in a variety of nonaqueous solvents. Shay and co-workers (7) have reported that Ir oxide is electroactive in solutions of $\mathrm{KOH}$ or $\left(\mathrm{CH}_{3}\right)_{4} \mathrm{NOH}$ in ethanol or acetonitrile, but not in solutions of $\mathrm{HClO}_{4}$ or $\mathrm{H}_{2} \mathrm{SO}_{4}$ in DMSO or acetonitrile. Gottesfeld and McIntyre (2) have reported that Ir oxide is not electroactive in dry acetonitrile containing either $\mathrm{Bu}_{4} \mathrm{NClO}_{4}$ or $\mathrm{LiAsF}_{6}$. McIntyre et al. (8) demonstrated that $\mathrm{Li}^{+}$and $\mathrm{Na}^{+}$insertion into Ir oxide occurred in 2-methyl-tetrahydrofuran containing $\mathrm{LiAsF}_{6}$ and in propylene carbonate containing $\mathrm{NaAsF}_{6}$, respectively. However, the rate of charging and discharging of the oxide in these media was very slow. Pickup and Birss (9) have used chronocoulometry to investigate the kinetics of iridium oxide charge and discharge in $\mathrm{Li}^{+}$-containing acetonitrile solutions, and have suggested that ion transport in the oxide limits the charge/discharge kinetics.

In this work, we have attempted to optimize the conditions for Ir oxide electrochemistry in nonaqueous solvents. To this end, we have been able to significantly improve the kinetics of Ir oxide charging and discharging in a number of $\mathrm{Li}^{+}$-containing organic solutions.

\section{Experimental}

Electrochemistry.-All electrochemical experiments were carried out in conventional three-compartment glass cells under argon at room temperature. The working electrodes were $99.9 \%$ purity Ir wire (Johnson Matthey; $0.5 \mathrm{~mm}$ diam). The length of wire in contact

*Electrochemical Society Active Member.

'Present address: Department of Chemistry, Memorial University of Newfoundland, St. John's, Newfoundland, Canada A I B
$3 \times 7$. with the electrolyte was determined and controlled by the position of a polyethylene collar on the Ir wire, which was replaced between most sets of experiments (10).

The wire electrode was electrochemically cleaned before each experiment at ca. $2 \mathrm{~V} v s$. SSCE in $10 \% \mathrm{H}_{2} \mathrm{SO}_{4}$ for ca. $5 \mathrm{~min}$ and had a roughness factor of $2.4 \pm 0.2$ (10). Potential pulses into the hydrogen evolution region (e.g., $-0.7 \mathrm{~V}$ ) helped to remove oxide remaining from the previous experiment. All electrode areas used in this paper are geometric areas.

Counterelectrodes were $\mathrm{Pt}$ gauze or wire and SCE, $\mathrm{SSCE}$, or $\mathrm{Ag} / \mathrm{Ag}^{+}$reference electrodes were used. All potentials are quoted relative to the SSCE $(+236 \mathrm{mV} v s$. NHE).

An EG\&G PARC 173 potentiostat was used with a PARC 175 Universal Programmer and a PARC 179 digital coulometer. Voltammograms were recorded on a Hewlett-Packard 7044A X-Y recorder.

Scanning electron microscopy.-Scanning electron microscopy was performed using a Cambridge Stereoscan 2500 . The oxide coated electrode was soaked in water for $10 \mathrm{~min}$ and dried in air before the SEM study. It was not coated with gold or graphite prior to examination with the SEM.

General--Aldrich Gold Label acetonitrile, tetrahydrofuran and 1,3-dioxolane, and reagent grade propylene carbonate were dried over molecular sieves (Fisher; $4 \AA$ ) before use. $\mathrm{LiClO}_{4}$ (Fisher) was dried at $60^{\circ} \mathrm{C}$ in a vacuum. $\mathrm{LiBF}_{4}$ (Aldrich) was used as received. Other reagents were reagent grade (Fisher) or better and were also used as received.

\section{Results and Discussion}

Ir oxide in acetonitrile/ $\mathrm{LiClO}_{4}-$ Since $\mathrm{Li}^{+}$insertion (and expulsion) into Ir oxide occurs during discharging (and charging) of Ir oxide in neutral aqueous $\mathrm{LiClO}_{4}$ solutions (6), this medium was chosen for growth of the Ir oxide films in most of this work. The rate of Ir oxide film growth in neutral $\mathrm{LiClO}_{4}$ solutions as a function of time (number of cycles) and the potential limits has been investigated (11), in comparison with Ir oxide growth in alkaline and acidic solutions. It was found (11) that growth in neutral solutions results in Ir oxide films that are less hydrated and more stable than those produced in $0.5 \mathrm{M}$ $\mathrm{H}_{2} \mathrm{SO}_{4}$. Generally, 0.01M Na $\mathrm{B}_{4} \mathrm{O}_{7}$ ( $p \mathrm{H} 9$ buffer) was added to the $\mathrm{LiClO}_{4}$ solution to prevent large $p \mathrm{H}$ changes during oxide growth (11).

Figure 1 shows a cyclic voltammogram of an iridium electrode with an approximately $1 \mu \mathrm{m}$ thick Ir oxide film, in this growth medium ( $\left.1 M \mathrm{LiClO}_{4} / 0.01 M \mathrm{Na}_{2} \mathrm{~B}_{4} \mathrm{O}_{7}\right)$ $\left(-\right.$ ). The cathodic peak at $-0.43 \mathrm{~V}$ is due to both $\mathrm{H}^{+}$ (peak) and $\mathrm{Li}^{+}$(shoulder) insertion into the oxide as the Ir sites are reduced from $\operatorname{Ir}($ IV) to $\operatorname{Ir}($ III). The anodic peaks at -0.12 and $+0.93 \mathrm{~V}$ are due to $\mathrm{Li}^{+}$and $\mathrm{H}^{+}$expulsion, respectively, during oxidation of the oxide (6). It is 


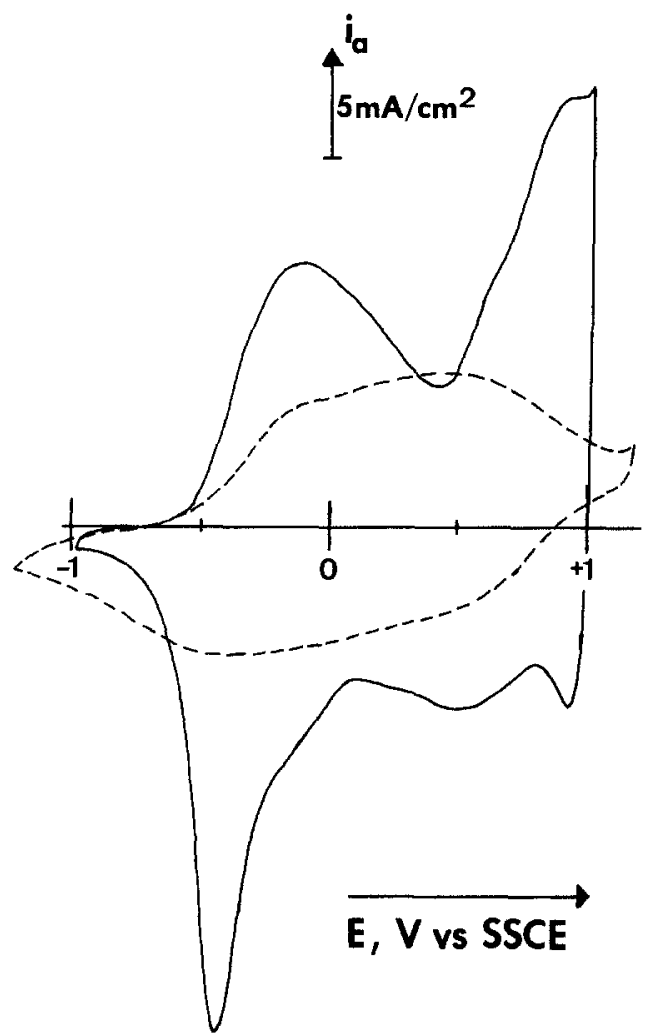

Fig. 1. Cyclic voltammograms $(100 \mathrm{mV} / \mathrm{s}$ ) of Ir oxide (grown in $1 \mathrm{M}$ $\mathrm{LiClO}_{4} / 0.01 \mathrm{M} \mathrm{Na}_{2} \mathrm{~B}_{4} \mathrm{O}_{7}, \mathrm{ca} .1 \mu \mathrm{m}$ thick) in the aqueous growth medium $(-)$ and in $1 \mathrm{M} \mathrm{LiClO} / \mathrm{CH}_{3} \mathrm{CN}(-\ldots)$.

clear from the voltammogram in Fig. 1 (-) that approximately $50 \%$ of the oxide reacts via each of these two mechanisms, under these conditions.

Also shown in Fig. 1 is a voltammogram of this same electrode in $1 M \mathrm{LiClO}_{4} / \mathrm{CH}_{3} \mathrm{CN}$ (- - ). The electrode, with the oxide in the $\operatorname{Ir}(\mathrm{IV})$ state, was rinsed with water and acetone, but was not allowed to dry during transfer from the neutral aqueous solution to the acetonitrile. Oxide films which had been dried prior to study in the nonaqueous solutions gave inferior electrochemical results (see below).

The voltammogram of Ir oxide in acetonitrile shown in Fig. 1 exhibits an envelope of quasi-reversible redox waves centered at $c a .0 \mathrm{~V}$ and covering an approximately $2 \mathrm{~V}$ potential range. The anodic and cathodic charges in this voltammogram are approximately equal and correspond to ca. $50 \%$ of the charge in the voltammogram in aqueous solution [Fig.1 $1(-)$ ]. Under optimum conditions, the charge capacity in $\mathrm{CH}_{3} \mathrm{CN}$ equals that in aqueous solution (see below). The Ir oxide films were electrochromic in $\mathrm{CH}_{3} \mathrm{CN}$, being black while oxidized and light gray while reduced, as had been observed in aqueous media $(2,7)$.

Figure 2 shows several voltammograms of the same electrode in the same $\mathrm{CH}_{3} \mathrm{CN}$ solution as in Fig. 1 but at lower scan rates $(s)$, and with the current scale sensitivity (S) adjusted so that $S / \mathrm{s}$ is constant. At $1 \mathrm{mV} / \mathrm{s}$, the voltammogram is more reversible than that at $100 \mathrm{mV} / \mathrm{s}$ and resembles that obtained in aqueous $\mathrm{LiClO}_{4}$ [Fig. 1 ( but with the sharp cathodic peak attributed to $\mathrm{H}^{+}$insertion (cathodic peak potential $=E_{\mathrm{pc}}=-0.43 \mathrm{~V}$ ) and the anodic peak at $+0.93 \mathrm{~V}$ attributed to $\mathrm{H}^{+}$expulsion now absent. The peak potentials at $1 \mathrm{mV} / \mathrm{s}$ in acetonitrile $\left(E_{\text {pa }}\right.$ $=-0.30 \mathrm{~V} ; E_{\mathrm{pc}}=-0.4 \mathrm{~V}$ ) are close to those observed for $\mathrm{Li}^{+}$insertion and expulsion, at $100 \mathrm{mV} / \mathrm{s}$ in the aqueous solution $\left(E_{\mathrm{pa}}=-0.12 \mathrm{~V} ; E_{\mathrm{pc}} \sim-0.3 \mathrm{~V}\right)$. Also, the charge capacity of the oxide is now approximately the same in both solutions.

The voltammograms of Ir oxide in acetonitrile can, thus, be interpreted as involving $\mathrm{Li}^{+}$insertion during reduction of $\operatorname{Ir}(\mathrm{IV})$ to $\operatorname{Ir}(\mathrm{III})$ and $\mathrm{Li}^{+}$expulsion during oxidation. The broadness of the voltammograms is caused

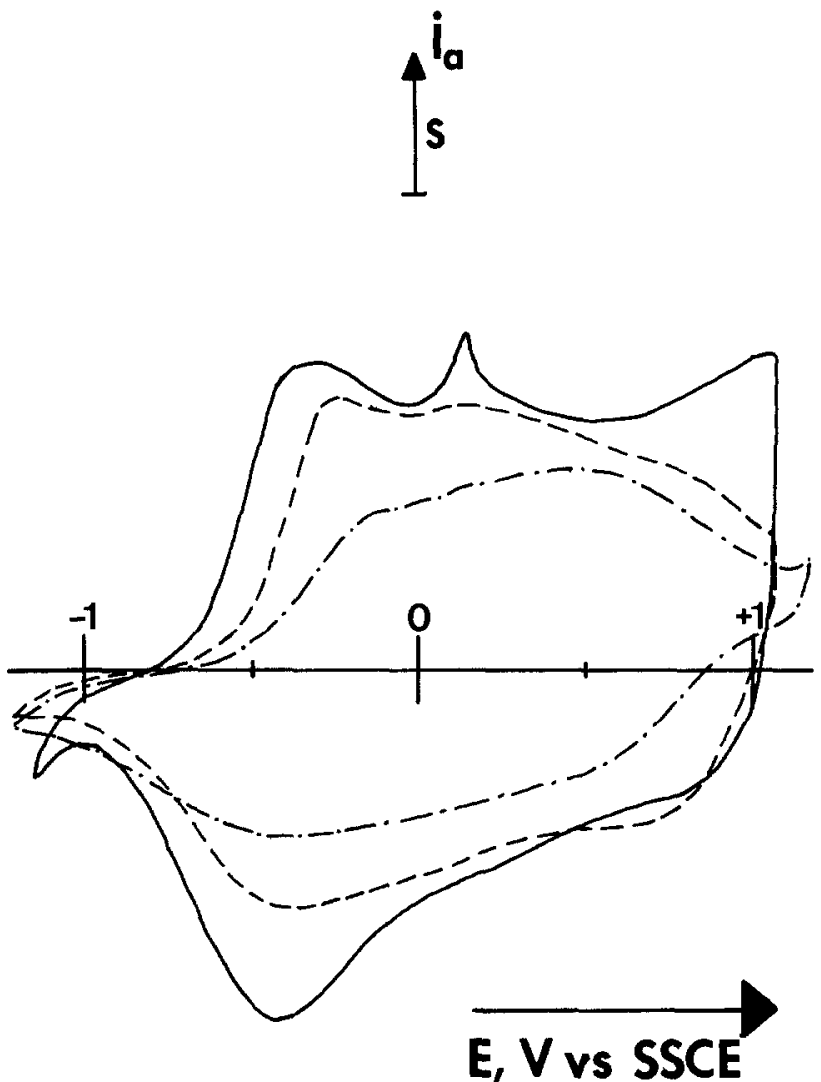

Fig. 2. Cyclic voltammograms of Ir oxide (grown in $1 M$ $\mathrm{LiClO}_{4} / 0.01 \mathrm{M} \mathrm{Na} \mathrm{B}_{4} \mathrm{O}_{7}$, ca. $1 \mu \mathrm{m}$ thick) in $1 \mathrm{M} \mathrm{LiClO} / \mathrm{CH}_{3} \mathrm{CN}$ at 1 $\mathrm{mV} / \mathrm{s}(\longrightarrow), 10 \mathrm{mV} / \mathrm{s}(--)$, and $100 \mathrm{mV} / \mathrm{s}(-\cdots) . \mathrm{S}=0.05,0.5$, and $5 \mathrm{~mA} / \mathrm{cm}^{2}$, respectively. The small oxidation peak at $+0.15 \mathrm{~V}$ in the $1 \mathrm{mV} / \mathrm{s}$ voltammogram is due to trace $\mathrm{Ag}^{+}$from the reference electrode.

by a number of overlapping redox waves which presumably result from the presence of a range of Ir sites within the oxide film.

In order to verify the involvement of $\mathrm{Li}^{+}$in the electrochemical charging and discharging of Ir oxide in $\mathrm{LiClO}_{4} /$ $\mathrm{CH}_{3} \mathrm{CN}$, a number of experiments were first performed in the absence of $\mathrm{Li}^{+}$before transfer to a $\mathrm{Li}^{+}$-containing $\mathrm{CH}_{3} \mathrm{CN}$ solution.

An Ir oxide film was grown at Ir in aqueous $1 M \mathrm{LiClO}_{4}$ (no buffer) and a voltammogram in this medium is shown in Fig. 3A [cf. Fig. 1 (-)]. The electrode was then rinsed with water and acetone, transferred to acetonitrile containing $\mathrm{Et}_{4} \mathrm{NClO}_{4}$, and the voltammogram shown in Fig. 3B was then obtained. Water was then added to the acetonitrile (ca. $2 \%$ ) and the voltammogram shown in Fig. 3C was obtained. Finally, the electrode was rinsed again with acetone and transferred to dry acetonitrile containing $\mathrm{LiClO}_{4}$. The voltammogram shown in Fig. 3D was obtained after several potential cycles including a scan of the potential to $+1.6 \mathrm{~V}$ (see below).

Figure 3 shows that reversible oxidation and reduction of Ir oxide in acetonitrile in the potential range of -0.5 to $+0.5 \mathrm{~V}$ does not occur significantly when $\mathrm{Et}_{4} \mathrm{~N}^{+}, \mathrm{ClO}_{4}^{-}$, and/or $\mathrm{H}_{2} \mathrm{O}$ are the only additives to the acetonitrile. However, it does occur when $\mathrm{Li}^{+}$is added (Fig. 3D). The lack of electrochemical response in Fig. 3B in the absence of $\mathrm{Li}^{+}$or water shows that $\mathrm{Et}_{4} \mathrm{~N}^{+}$and $\mathrm{ClO}_{4}^{-}$may be too large for rapid insertion into and expulsion from $\mathrm{Ir}$ oxide in acetonitrile.

Figure 3C shows the electrochemical response of Ir oxide to trace water in acetonitrile. The cathodic peak at $-1.04 \mathrm{~V}$ is presumably due to $\mathrm{H}^{+}$(from the water) insertion into the oxide, while the anodic peak at $+1.06 \mathrm{~V}$ can be attributed to $\mathrm{H}^{+}$expulsion. This response with $2 \%$ $\mathrm{H}_{2} \mathrm{O}$ added is qualitatively similar to the response due to $\mathrm{H}^{+}$in neutral aqueous solutions (see discussion of Fig. 1) $(6,11)$. Clearly, $\mathrm{H}^{+}$insertion and expulsion is not responsible for the electrochemical response observed in Fig. 2. 


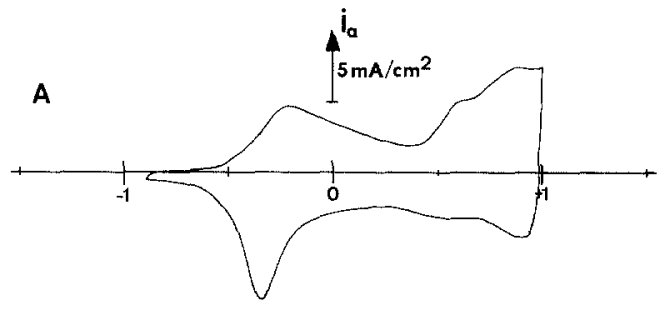

B
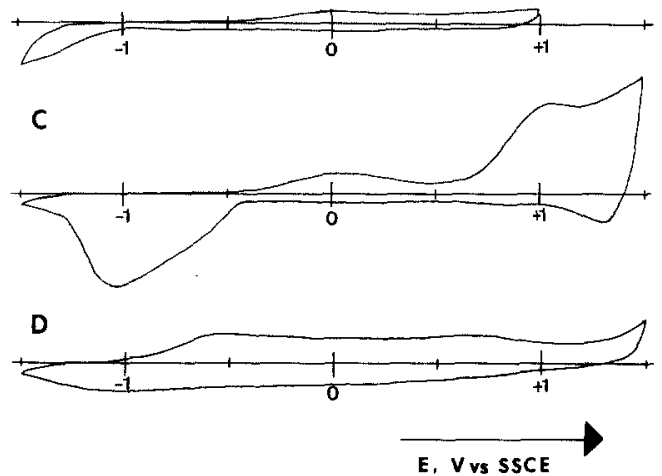

Fig. 3. Cyclic voltammograms $(100 \mathrm{mV} / \mathrm{s}$ ) of Ir oxide (grown in aqueous $1 \mathrm{M} \mathrm{LiClO}_{4}$, ca. $0.5 \mu \mathrm{m}$ thick) in the growth medium (A), $0.1 \mathrm{M}$ $\mathrm{Et}_{4} \mathrm{NClO}_{4} / \mathrm{CH}_{3} \mathrm{CN}(\mathrm{B}), 0.1 \mathrm{M} \mathrm{Et} \mathrm{NClO}_{4} / \mathrm{CH}_{3} \mathrm{CN}+\mathrm{ca} .2 \% \mathrm{H}_{2} \mathrm{O}(\mathrm{C})$, and in $0.1 \mathrm{M} \mathrm{LiClO}_{4} / \mathrm{CH}_{3} \mathrm{CN}(\mathrm{D})$.

The electrochemical response in Fig. 3D must be due primarily to $\mathrm{Li}^{+}$insertion and expulsion since $\mathrm{Li}^{+}$is the only species which was not present in the experiments of Fig. 3B and C. The response shown in Fig. 3D is not optimum for Ir oxide in $0.1 \mathrm{M} \mathrm{LiClO} / \mathrm{CH}_{3} \mathrm{CN}$. As has just been discussed, this electrode had been used in a variety of solutions and had probably suffered some structural damage or changes.

The initial response of the Ir oxide coated electrode when first transferred from wet $\mathrm{Et}_{4} \mathrm{NClO}_{4} / \mathrm{CH}_{3} \mathrm{CN}$ (Fig. 3C) to dry $\mathrm{LiClO}_{4} / \mathrm{CH}_{3} \mathrm{CN}$ (Fig. 3D) was particularly interesting. Initially, the response between -1.5 and $+1 \mathrm{~V}$ was almost identical to that shown in Fig. 3B for Ir oxide in dry $\mathrm{Et}_{4} \mathrm{NClO}_{4} / \mathrm{CH}_{3} \mathrm{CN}$. When the potential was scanned up to $+1.6 \mathrm{~V}$, a large irreversible anodic peak, similar to that at $+1.06 \mathrm{~V}$ in wet $\mathrm{Et}_{4} \mathrm{NClO}_{4} / \mathrm{CH}_{3} \mathrm{CN}$ (Fig. 3C) was observed at ca. $+1.1 \mathrm{~V}$. The voltammogram shown in Fig. 3D was then obtained. Thus, it appears that $\mathrm{H}^{+}$must first be expelled from the oxide at $E_{\mathrm{pa}}=+1.1 \mathrm{~V}$ before $\mathrm{Li}^{+}$ insertion can occur.

Optimization of Ir oxide charging, discharging, and stability in acetonitrile.-The voltammograms shown in Fig. 2 were achieved by growth of the oxide in aqueous $1 M \mathrm{LiClO}_{4}$ (buffered at $p \mathrm{H} \sim 9$ ) and by not allowing the oxide to dry out during transfer to the acetonitrile solution. This procedure has consistently yielded Ir oxide films with excellent stability, high charge capacity, and rapid charging/discharging kinetics in $\mathrm{LiClO}_{4} / \mathrm{CH}_{3} \mathrm{CN}$.

Cycling of the potential above $+1 \mathrm{~V}$ in acetonitrile, into an irreversible oxidation wave, increases the reversible charge capacity of the oxide, whereas cycling below ca. $-1.5 \mathrm{~V}$, into an irreversible reduction wave, causes a decrease in this capacity. This behavior is probably due to a competition between $\mathrm{H}^{+}$(from trace water) and $\mathrm{Li}^{+}$insertion into the oxide. At potentials above $+1 \mathrm{~V}, \mathrm{H}^{+}$is expelled from the oxide (see above, Fig. 3C), increasing the number of oxidized sites within the oxide. Reduction of the oxide at potentials above $-1.5 \mathrm{~V}$ causes $\mathrm{Li}^{+}$, but not $\mathrm{H}^{+}$, insertion to occur and so the charge capacity for $\mathrm{Li}^{+}$ insertion/expulsion (reversible) is increased. At potentials below $-1.5 \mathrm{~V}, \mathrm{H}^{+}$insertion can occur and this reduces the number of sites available for $\mathrm{Li}^{+}$insertion and, hence, decreases the anodic current in the next sweep as less $\mathrm{Li}^{+}$is expelled.

Tests of the stability of Ir oxide in acetonitrile have in dicated that there is no inherent instability to potential cycling. Loss of charge capacity, when observed, has been due to drying of the oxide between experiments or to cycling of the potential below $-1.5 \mathrm{~V}$ (see above).

The voltammograms shown in Fig. 4 exemplify some of the points discussed above. The oxide film was grown in aqueous $1 M \mathrm{LiClO}_{4} / \mathrm{Na}_{2} \mathrm{~B}_{4} \mathrm{O}_{7}$ and transferred to $1 M$ $\mathrm{LiClO} / \mathrm{CH}_{3} \mathrm{CN}$ without being dried. The charge capacity was increased after ten cycles of the potential between $-0.85 \mathrm{~V}$ and an increasing upper potential limit of up to $+1.95 \mathrm{~V}$ at $100 \mathrm{mV} / \mathrm{s}$. Note that the voltammogram obtained after optimization is displayed at double the current sensitivity as compared to the other two voltammograms.

A direct comparison between the charge capacities of the oxide in the aqueous growth medium and in acetonitrile is not a simple matter. The voltammogram in the growth medium contains charge contributions due to the $\mathrm{Ir}(\mathrm{III} / \mathrm{IV})$ couple and to $\mathrm{O}_{2}$ evolution $(1,11)$. In acetonitrile, $\mathrm{O}_{2}$ evolution does not take place and the potential of the Ir(III/IV) couple is unknown. The upper potential limit that should be used for integration of the current to obtain the charge capacity is, therefore, unknown in both cases.

To make a comparison between the two media, the following potential limits were chosen. In the growth medium, the anodic current was integrated up to the current minimum immediately preceding the sharp rise in current due to $\mathrm{O}_{2}$ evolution $(+0.69 \mathrm{~V})$. The charge up to this limit corresponds to approximately one electron per Ir atom in the oxide film (11). In acetonitrile, the current minimum immediately preceding the increase due to $\mathrm{H}^{+}$ expulsion $[+0.96$ for Fig. $4(-\cdots)$ or $+1.28 \mathrm{~V}$ for Fig. 4 (-)] was chosen for the integration limit.

Using these integration limits, the charge capacity of the oxide film was $0.18,0.13$, and $0.19 \mathrm{C} / \mathrm{cm}^{2}$ in the growth medium, in acetonitrile initially, and after optimization in acetonitrile, respectively.

Obviously, charge capacities comparable to those obtained in aqueous media can be obtained in acetonitrile. However, the high charge capacity following optimization in acetonitrile could not be maintained during cycling over the potential range used for the voltammogram shown in Fig. 4 ( $\longrightarrow$ ). Following seven subsequent cycles of potential after the recording of Fig. 4 (-), the charge capacity of the oxide film had

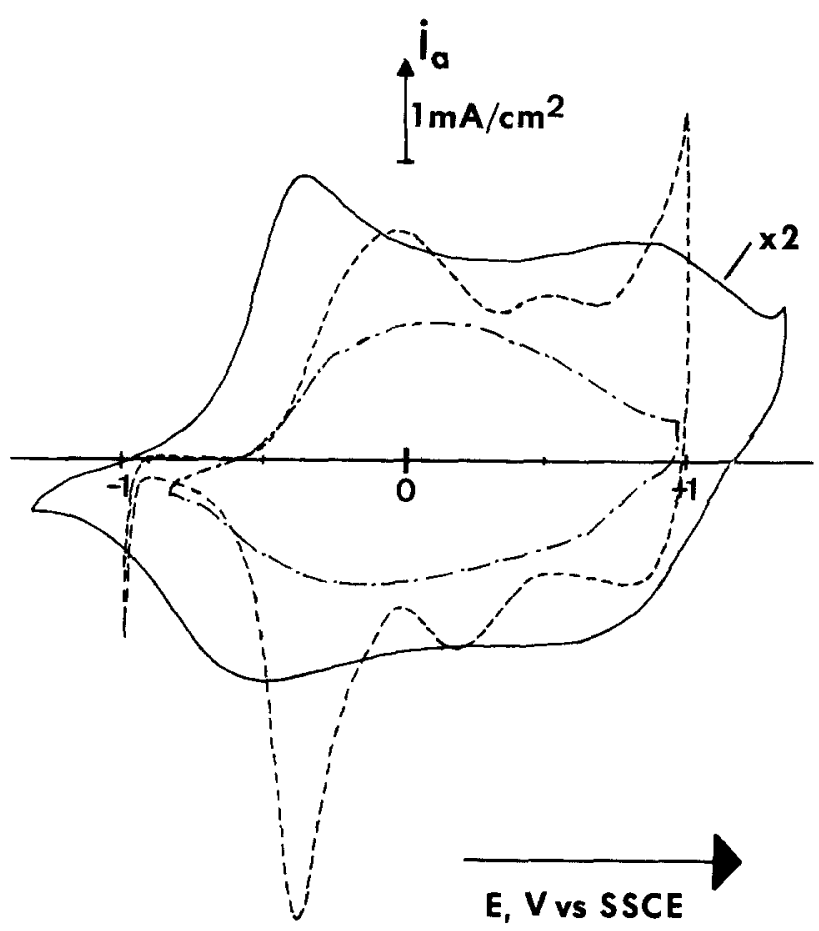

Fig. 4. Cyclic voltammograms $(10 \mathrm{mV} / \mathrm{s})$ of Ir oxide (grown in $1 M$ $\mathrm{LiClO}_{4} / 0.01 \mathrm{M} \mathrm{Na}_{2} \mathrm{~B}_{4} \mathrm{O}_{7}, \mathrm{ca} .2 \mu \mathrm{m}$ thick) in the growth medium (- - -) and in $1 \mathrm{M} \mathrm{LiClO}_{4} / \mathrm{CH}_{3} \mathrm{CN}$, initially $(\cdots-$ - ) and after ten potential cycles with the upper potential limit having been progressively increased to $+1.95 \mathrm{~V}(-$ - 

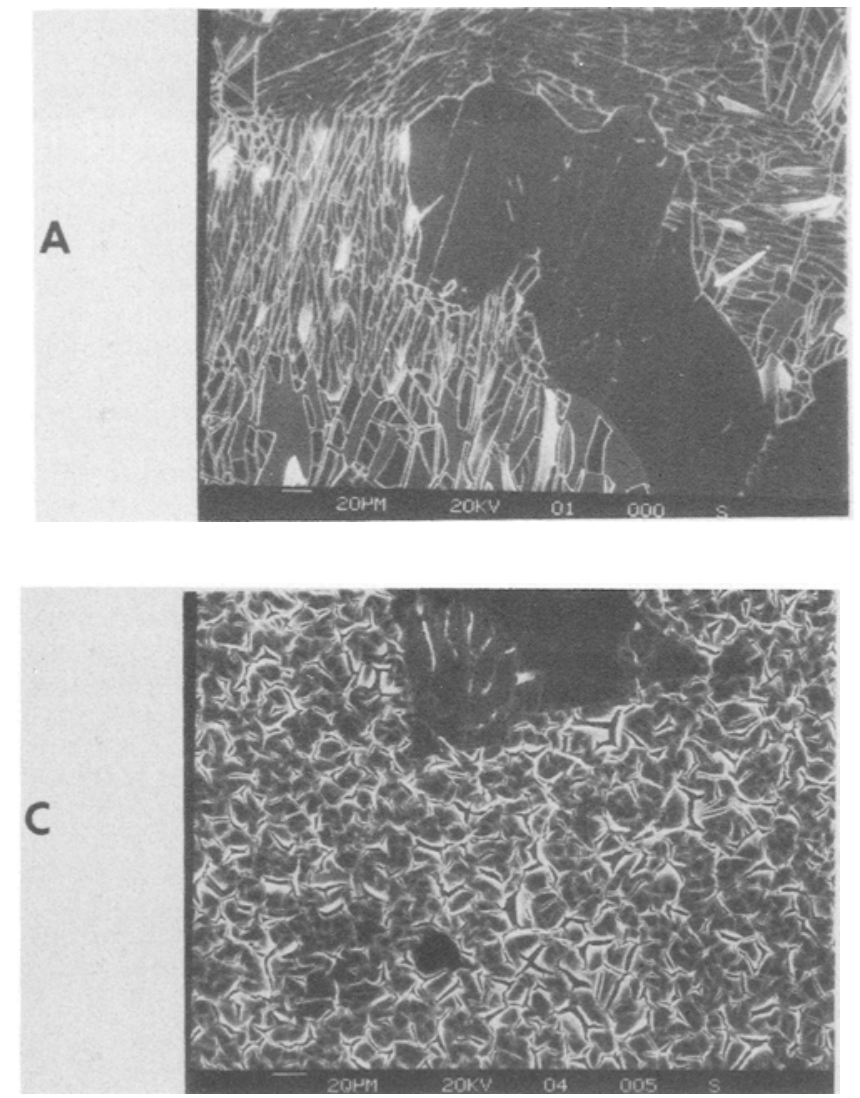

dropped to $0.13 \mathrm{C} / \mathrm{cm}^{2}$ (integrated to $+1.11 \mathrm{~V}$ ). The development of an irreversible oxidation wave at the anodic potential limit indicated that $\mathrm{H}^{+}$insertion into the oxide was occurring at the cathodic end of the cycle. This was presumably reponsible for the reduced capacity for $\mathrm{Li}^{+}$ insertion. It can be seen from Fig. $3 \mathrm{C}$ that $\mathrm{H}^{+}$insertion and expulsion can occur within the potential limits of Fig. 4 (- $)$.

By the time the voltammogram shown in Fig. 4 (- - ) was recorded, the Ir oxide had been in acetonitrile for $4 \mathrm{~h}$ under continuous potential cycling conditions $(1,10$, and $100 \mathrm{mV} / \mathrm{s}$; cathodic limit as low as $-1.6 \mathrm{~V}$; anodic limit was as high as $+1.95 \mathrm{~V})$. Obviously, the stability of the oxide under these conditions is excellent.

Inferior results have been obtained when Ir oxide films have been grown in $0.5 \mathrm{M} \mathrm{H}_{2} \mathrm{SO}_{4}$, rather than aqueous $\mathrm{LiClO}_{4}$, and then transferred to acetonitrile. This appears to be due to poor adhesion of these films to the electrode surface $(11,12)$. The scanning electron micrograph shown in Fig. 5A clearly shows that Ir oxide grown in $0.5 \mathrm{M} \mathrm{H}_{2} \mathrm{SO}_{4}$ tends to be cracked and does not adhere well to the electrode surface. Films grown in aqueous $\mathrm{LiClO}_{4}$ exhibit a significantly greater mechanical stability, are more adherent, and less susceptible to cracking (Fig. 5B). The pattern of cracking and flaking of the oxide film shown in Fig. 5A is interesting. The large area in the center of the micrograph is not cracked at all, whereas much of the oxide in the bottom left corner has been lost from the electrode surface. This latter area was more characteristic of the major part of the electrode surface. The reasons for these variations on the surface of the same electrode are not clear.

In one case, a film grown in $0.5 \mathrm{M} \mathrm{H}_{2} \mathrm{SO}_{4}$ initially gave a response in acetonitrile that was very similar to that shown in Fig. 2. However, this response rapidly deteriorated and at the end of the experiment, the film could be washed from the electrode with a jet of water.

Critical point drying (13), which is a method of drying samples with a minimum of damage, has been found to promote adhesion of Ir oxide films to the electrode (11). A film grown in $0.5 \mathrm{M} \mathrm{H}_{2} \mathrm{SO}_{4}$ and dried by this method gave a very good and stable response in acetonitrile.

Ir oxide growth in acetonitrile/water mixtures.-We have also investigated the effect of acetonitrile on the

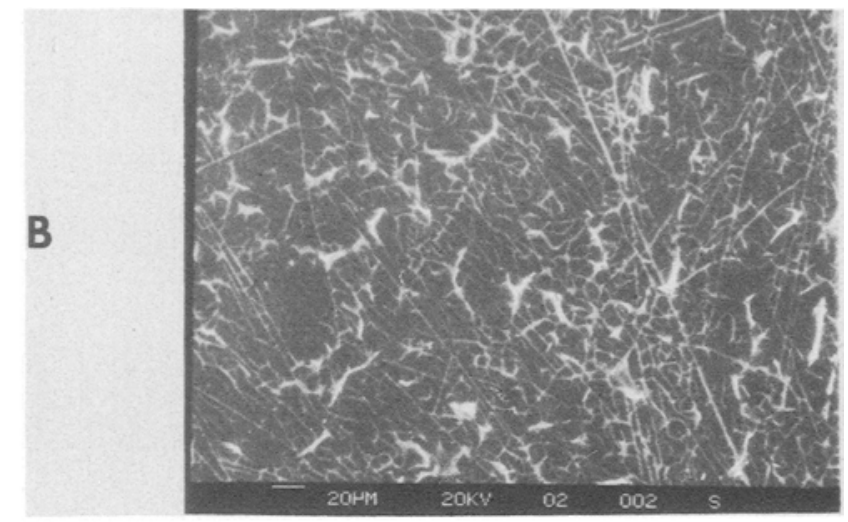

Fig. 5. Scanning electron micrographs of approximately $1 \mu \mathrm{m}$ thick anodic ir oxide films grown in $0.5 \mathrm{M} \mathrm{H}_{2} \mathrm{SO}_{4}(\mathrm{~A})$, aqueous $1 \mathrm{M}$ $\mathrm{LiClO}_{4} / 0.01 \mathrm{M} \mathrm{Na} \mathrm{B}_{4} \mathrm{O}_{7}(\mathrm{~B})$, and $50 \%$ aqueous $\mathrm{CH}_{3} \mathrm{CN} / 1 \mathrm{M} \mathrm{LiClO}{ }_{4}(\mathrm{C})$.

growth of Ir oxide in aqueous solutions. It was anticipated that the presence of $\mathrm{CH}_{3} \mathrm{CN}$ in the growth medium would generate an oxide that exhibited improved behavior in dry $\mathrm{CH}_{3} \mathrm{CN}$ as compared to oxides grown in purely aqueous solutions.

It was found that the addition of $10 \%$ or $50 \% \mathrm{CH}_{3} \mathrm{CN}$ to aqueous $1 \mathrm{M} \mathrm{LiClO}_{4}$ did not appear to interfere with the Ir oxide growth process, although oxide films grown in 50\% $\mathrm{CH}_{3} \mathrm{CN} / \mathrm{H}_{2} \mathrm{O}$ containing $1 M \mathrm{LiClO}_{4}$ tended to become detached from the electrode during growth or drying. The addition of $90 \% \mathrm{CH}_{3} \mathrm{CN}$ prevented Ir oxide growth altogether.

The scanning electron microscopy photographs shown in Fig. 5B and $5 \mathrm{C}$ clearly show that the presence of $\mathrm{CH}_{3} \mathrm{CN}$ in the growth medium (Fig. 5C) has a marked effect on the oxide structure. The film grown in $50 \%$ aqueous $\mathrm{CH}_{3} \mathrm{CN} / \mathrm{LiClO}_{4}$ (Fig. $5 \mathrm{C}$ ) is considerably more cracked and less adherent than that grown in aqueous $\mathrm{LiClO}_{4}$ (Fig. 5B).

Also, a film grown in $50 \%$ aqueous $\mathrm{CH}_{3} \mathrm{CN} / \mathrm{LiClO}_{4}$ exhibited a very low charge capacity and poor kinetics when subsequently transferred to dry acetonitrile containing $\mathrm{LiClO}_{4}$. The response deteriorated with time and after the experiment, the film could be readily washed from the electrode with a jet of water. It appears that the poor adhesion of films grown in this medium makes them unsuitable for use in nonaqueous solutions.

Ir oxide electrochemistry in other solvents.-Figure 6 shows voltammograms of an Ir oxide film in $1 \mathrm{M} \mathrm{LiClO}_{4}$ in propylene carbonate and in $1 M \mathrm{LiBF}_{4}$ in tetrahydrofuran. In $\mathrm{PC} / \mathrm{LiClO}_{4}$, the voltammogram of Ir oxide is almost identical to its voltammogram in $\mathrm{CH}_{3} \mathrm{CN} / \mathrm{LiClO}$. However, in $\mathrm{THF} / \mathrm{LiBF}_{4}$, the charge/discharge process is shifted positively by about $0.5 \mathrm{~V}$ and the kinetics are somewhat slower (note the different scan speeds in Fig. 6). In 1,3-dioxolane/1M LiBF ${ }_{4}$ and $\mathrm{CH}_{3} \mathrm{CN} / 1 M \mathrm{LiBF}$, voltammograms similar to that obtained in $\mathrm{THF} / \mathrm{LiBF}_{4}$ were obtained. Ir oxide was electrochromic in all of these solutions.

These results show that it is the electrolyte, rather than the solvent, which has the greatest effect upon the Ir oxide voltammogram in these cases. Further investigation revealed that $\mathrm{LiBF}_{4}$ is hydrolyzed (14) by trace water in these solvents to produce an acidic solution. Thus, the 


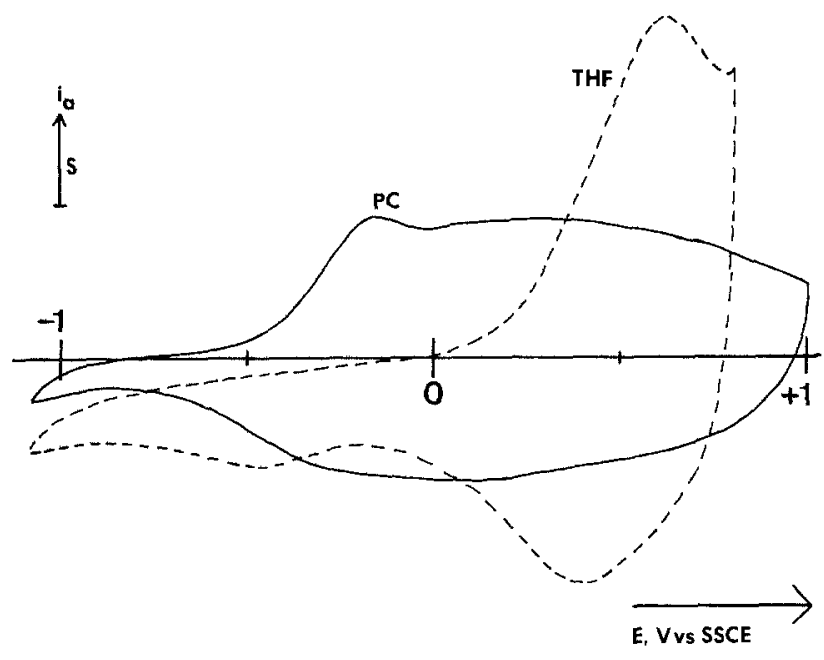

Fig. 6. Cyclic voltammograms of Ir oxide (grown in aqueous $1 M$ $\mathrm{LiClO}_{4} / 0.01 \mathrm{M} \mathrm{Na} \mathrm{B}_{4} \mathrm{O}_{7}$ ca. $0.2 \mu \mathrm{m}$ thick) in propylene carbonate $/ 1 \mathrm{M}$ $\mathrm{LiClO}_{4}\left(-; 10 \mathrm{mV} / \mathrm{s} ; \mathrm{S}=0.1 \mathrm{~mA} / \mathrm{cm}^{2}\right)$ and in $\mathrm{THF}_{1} / \mathrm{M} \mathrm{LiBF}_{4}(-\cdots$ $\left.1 \mathrm{mV} / \mathrm{s} ; \mathrm{S}=0.01 \mathrm{~mA} / \mathrm{cm}^{2}\right)$.

potential shift in THF (Fig. 6) is probably due to the different $\mathrm{H}^{+}$concentration of this solution as compared to that of $\mathrm{PC}(15,16)$.

\section{Conclusions}

Iridium oxide films, grown in neutral aqueous $\mathrm{LiClO}_{4}$ solutions, have been found to exhibit very good charge capacities and oxidation/reduction kinetics in $\mathrm{Li}^{+}$containing $\mathrm{CH}_{3} \mathrm{CN}$ solutions. The oxide is electrochromic in this nonaqueous medium and yields very similar charge capacities as in the aqueous growth medium. Ir oxide reduction and oxidation in $\mathrm{CH}_{3} \mathrm{CN}$ takes place with the insertion and expulsion, respectively, of $\mathrm{Li}^{+}$ions, comparable to the situation in neutral, aqueous $\mathrm{Li}^{+}$-containing solutions.

In optimizing the electrochemical response of Ir oxide films in $\mathrm{CH}_{3} \mathrm{CN}$, it was found to be very important to prevent the drying out of the oxide when transferring it from the aqueous growth medium to $\mathrm{CH}_{3} \mathrm{CN}$. Also, the potential limits utilized in $\mathrm{CH}_{3} \mathrm{CN}$ are important in maintaining the maximum charge capacity. Growth of Ir ox- ide films in aqueous $\mathrm{H}_{2} \mathrm{SO}_{4}$ or in mixtures of aqueous/ $\mathrm{CH}_{3} \mathrm{CN}$ solutions led to diminished electrochemical performance in $\mathrm{CH}_{3} \mathrm{CN}$. SEM investigations showed that these oxides had a more cracked structure and were less adherent than those grown in neutral aqueous $\mathrm{LiClO}_{4}$ solutions.

The electrochemical behavior of Ir oxide has also been studied in PC and THF. Although the oxide is electrochromic in both of these solvents, the oxide shows somewhat slower kinetics in THF than in $\mathrm{PC}$ and $\mathrm{CH}_{3} \mathrm{CN}$.

\section{Acknowledgment}

We gratefully acknowledge financial support from Allied Canada Incorporated and the Natural Sciences and Engineering Research Council of Canada.

Manuscript submitted Jan. 20, 1987; revised manuscript received June $29,1987$.

University of Calgary assisted in meeting the publication costs of this article.

\section{REFERENCES}

1. L. D. Burke, in "Electrodes of Conductive Metallic OXides," Part A, S. Trasatti, Editor, Elsevier Publishing Co., New York (1980).

2. S. Gottesfeld and J. D. E. MeIntyre, This Journal, 126, 742 (1979).

3. J. Mozota and B. E. Conway, Electrochim. Acta., 28, 9 (1983).

4. L. D. Burke and D. P. Whelan, J. Electroanal. Chem., 162, 121 (1984).

5. L. D. Burke and R. A. Scannell, ibid, 175, 119 (1984).

6. P. G. Pickup and V. I. Birss, ibid., Accepted.

7. G. Beni, C. E. Rice, and J. L. Shay, This Journal, 127, $1342(1980)$.

8. J. D. E. McIntyre, S. Basu, W. F. Peck, Jr., W. L. Brown, and W. M. Augustyniak, Phys. Rev. B, 25, 7242 (1982).

9. P. G. Pickup and V. I. Birss, J. Electroanal. Chem., Accepted.

10. P. G. Pickup and V. I. Birss, ibid., 220, 83 (1987),

11. P. G. Pickup and V. I. Birss, ibid., Accepted.

12. J. Mozota and B. E. Conway, ibid., 128, 2142 (1981).

13. T. F. Anderson, Trans. N.Y. Acad. Sci., 13, 130 (1951).

14. C. A. Wamser, J. Am. Chem. Soc., 70, 1209 (1948).

15. M. F. Yuen, I. Lauks, and W. C. Dautremont-Smith, Solid State Ionics, 11, 19 (1983).

16. L. D. Burke, J. K. Mulcahy, and D. P. Whelan, J. Electroanal. Chem., 163, 117 (1984).

\title{
New Technique for Measurement of Electrode Strain during Electrochemical Reactions
}

\author{
M. A. Butler* and D. S. Ginley* \\ Sandia National Laboratories, Albuquerque, New Mexico 87185
}

\section{ABSTRAC'T}

A new technique, based on an optical fiber interferometer, is described for in situ measurement of electrode strain during electrode reactions. A model is presented which relates changes in optical path length of the fibers to the various strain components in the electrode. Measurements of strain associated with electrodeposition of nickel as a function of the thickness of the nickel layer are reported and compared to a simple model. Measurements of strain associated with the anodic oxidation of titanium are also reported. The strain generated in the titanium has a component which is independent of applied potential after oxide growth is complete and a component which is dependent on the applied potential The potential dependent term is identified as an electrostriction effect in the anodic oxide enhanced by the porous nature of the electrode. The potential independent term comes from compressive stress in the anodic oxide induced by the growth process.

In a recent accelerated brief communication (1) we reported a new technique for in situ measurement of electrode strain associated with electrode reactions. The basic concept utilizes a metal-coated optical fiber as the working electrode in an electrochemical cell, while simultaneously using the fiber as one arm of a Mach-

\footnotetext{
* Electrochemical Society Active Member.
}

Zehnder interferometer. The optical path length of this fiber can thus be monitored during the electrochemical reactions. Strain induced in the working electrode by these reactions will also strain the fiber and modify its effective optical path length. In this paper we expand the description of the technique and consider, in detail, models for relating the measured strain to the strain in the electrode itself. With this end in mind, we will dis- 